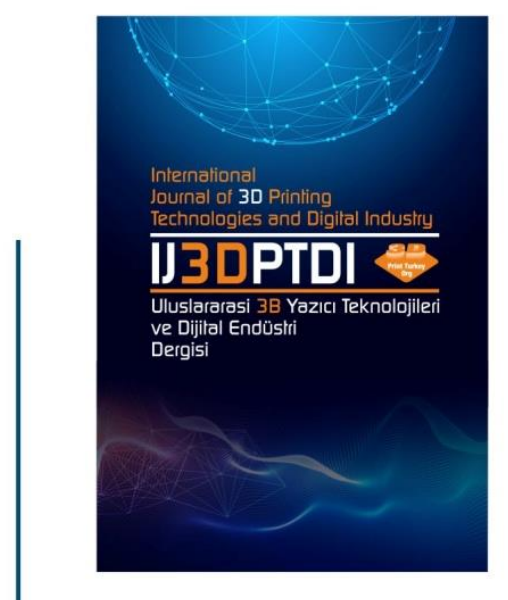

ULUSLARARASI 3B YAZICI TEKNOLOJILERI

VE DIJITAL ENDÜSTRI DERGISI

INTERNATIONAL JOURNAL OF 30 PRINTING TECHNOLOGIES AND DIGITAL INDUSTRY

I55N:2602-3350 [Online]

URL: https://dergipark.org.tr/ij3dptdi

\title{
CONCEPTUALIZATION OF THE PARADIGM "INTEGRATED TECHNOLOGIES AS A GLOBAL TREND IN THE DEVELOPMENT OF SHIPPING SAFETY OF AN INNOVATIVE SOCIETY"
}

Yazarlar (Authors): Nataliia Punchenko ${ }^{\mathbb{D}}$, Oleksandra Tsyra ${ }^{\mathbb{D}}$, Nadiia Kazakova ${ }^{\mathbb{D}}$ *

Bu makaleye şu şekilde atıfta bulunabilirsiniz (To cite to this article): Uygunoğlu T., Topçu I.B. "Conceptualization of The Paradigm "Integrated Technologies As a Global Trend Int he Development of Shipping Safety of An Innovative Society"'” Int. J. of 3D Printing Tech. Dig. Ind., 4(3): 278-284, (2020). 


\title{
CONCEPTUALIZATION OF THE PARADIGM "INTEGRATED TECHNOLOGIES AS A GLOBAL TREND IN THE DEVELOPMENT OF SHIPPING SAFETY OF AN INNOVATIVE SOCIETY"
}

\author{
Nataliia Punchenko ${ }^{a}$ (D), Oleksandra Tsyra ${ }^{b}$ (D), Nadiia Kazakova ${ }^{c}$ (iD* \\ ${ }^{a}$ Odessa State Academy of Technical Regulation and Quality University, Educational and Scientific Institute of \\ Metrology, Automation, Intellectual Technologies, and Electronics Faculty, Automated Systems and \\ Information-Measuring Technology Department, UKRAINE \\ ${ }^{b}$ O. S. Popov Odesa National Academy of Telecommunications University, Infocommunications and Software \\ Engineering Faculty, Communication Networks Department, UKRAINE \\ 'Odessa State Environmental University, Computer Science, Management and Administration Faculty, \\ Information Technologies Department, UKRAINE \\ *Corresponding Author: kaz2003@ukr.net
}

(Received: 06.06.2020; Revised: 17.12.2020; Accepted: 30.12.2020)

\begin{abstract}
The evolution of computer-integrated technologies as a global trend in developing the safety to navigation of the innovative society is presented. Computer integrated technologies contributed to the development of computer intelligence determined by the paradigm of information technology, which contributed to the formation of computer integrated navigation systems. It is revealed that a global phenomenon that is communicative in its scope organized according to the principle of an integration system, giving rise to the phenomenon of a control system. The emergence of a new global solution to navigation safety was facilitated by the emergence of a new form of a navigation system is a computer integrated navigation system. It is concluded that the new navigation system, which is led by integration today, is the key to safe navigation driven by computer-integrated technologies. Computer-integrated technologies are the source of reliability, security, and manageability in the age of innovation.
\end{abstract}

Keywords: Information Technology. Human Factor. Computer Integrated Systems. Safety Navigation.

\section{INTRODUCTION}

A high percentage of ship accidents at sea is an objective reality that cannot be denied and is due, initially, to the characteristics of external and internal factors accompanying navigation, which will always be present regardless of the human factor. The level of state and reliability of navigation in modern conditions, the real accuracy of navigation, and the quality of solving navigation problems are about half as bad as the norms. [1]. It follows that the complete elimination of the accident rate of ships has no chance. However, it is quite possible to influence the number of accidents with various measures and try to achieve its maximum relative reduction for a limited period. Such a fall in accident rate can be reached to a certain level, after which the accident rate will inevitably grow again or temporarily stabilize.

Tsymbal et al. investigated the integrated systems of flexible production technologies with sets and predicates techniques. Besides, all components of the systems were examined in detail. According to the results of these investigations, the proposed control systems using information technologies [2]. Dehgani et al. examined the relationship between supply chains and information technology. There are quite a lot of supply chains in the manufacturing industry. They investigated the positive and negative effects of information technologies on supply chains [3]. When the literature studies on computerintegrated technologies and information technology are examined, it is seen that there are many studies [4-9]. A favorable outcome for dealing with accidents can only suggest that this is a step forward to an acceptable level (with limited and permissible material damage), withholding accidents for a short period. 
We cannot forget that the accident rate and the material damage caused by the accident rate are not compatible and not interdependent. It is possible to assume that their relationship is inversely proportional. The fuzzy value of material damage does not make it possible to use it as a parameter providing a correct solution to identifying accident trends. Based on the annual analogy of indicators of absolute growth or reduction of material damage, we will receive an exclusively conditional idea of the current accident rate. Real bias may allow a relative accident rate to be observed. It's not a secret for anyone that the value of the indicator is numerically equal to the ratio of all emergencies, over the period being processed, to the total number of operated ships.

\section{SITUATIONAL APPROACH TO SAFETY NAVIGATION}

The accident of ships very often leads to the loss of human lives. It follows that not looking at the lack of any guarantee to achieve positive results in reducing accidents in general, the transport company (in water transport) is obliged to look for ways to deal with the causes of accidents. This kind of struggle is an urgent need drawn from the vital, production, moral interests of society. If it was possible to see the trend after the management system for the safe operation of ships in the company was used to reduce not even the number of accidents. However, the severity of these situations' consequences, then the management system for safe operation can be recognized as meeting the global aspiration of the society of skippers. The practice of modern navigation was able to show and prove that the desire to continually develop and improve the technical means of maritime navigation, ensuring the technical safety of ships remains an urgent problem in the maritime transport industry, and preventing accident rate remains actual. The statistics show a lot of not impressive moments, where one of the continually acting reasons can be traced, which leads to a ship accident, and most often, this is a human factor (operator of highrisk equipment or an entity controlling a moving object). It follows that it is necessary to direct efforts to prevent accidents in water transport and search for unused opportunities to reduce the high percentage of the "human factor" to the size of the world fleet's accident rate.

All the above pedals the relevance of solving the problem of safe water transport operation and the need to continue research on the problem, both theoretical and practical. The massive use of computer integrated technologies, which is carried out based on their application in marine control systems that ensure navigation safety, is the main content of the phenomenon that today is called navigation integration. It cannot be denied that, in its turn, computer integrated navigation technologies with the internationalization of new space technologies in the maritime activities could make it possible to fundamentally alter both the form and content of existing management techniques for safe operation and safe navigation in water transport. These technology changes could significantly affect the safety of marine navigation at the proper level and intensify the subsequent development of navigation control systems. When improving the methods of maintaining safe navigation at the required level, it is necessary to consider that monitoring is carried out in real-time from the ship's control system, without any preliminary or additional calculations. It can be seen, the dilemma of safe navigation is in the more rational use of computer integrated technologies, considering the properties of interaction and mutual understanding of the skipper with the intellectual product of navigation. The computer-integrated technologies included in the control systems significantly affect and give reason to think about such a task as replacing the organizational system for ensuring safe navigation with its analog - the computer intelligence.

To date, scientific and technological progress, the improvement of all types of human activities is associated with information technology and their use both for independent operations in production and management of the whole production process. Cyberization of management has become a mass phenomenon and a necessary condition for the existence of any business. In this sphere, in the process of its development, it began to raise the issue of developing optimal management decisions in a multilevel information management system. One of the cornerstone questions is the question of a control system in the form of a cognitive structure of distributed knowledge, which demonstrated the possibility of combining the professional knowledge of specialists and modern computers' intellectual capabilities [10]. It follows that informatization and computerization at this stage of modern navigation should be considered, not only as a strategic direction of scientific and technological progress, which should and solves problems to ensure safe navigation. It can be seen here that exceptional interest in finding a 
solution to ensuring navigation safety with minimizing the number of production risks associated with the "human factor" can be considered a specific synthesized theory of ergatic and intelligent systems. Such a theory studies and develops the logical and organizational forms of integrating the skipper with the complexes of intellectual activity tools containing scientific methods for processing information and making decisions, computer and information technology. To implement the industry strategy, new technological solutions related to the exchange of information will be introduced (Figure 1).

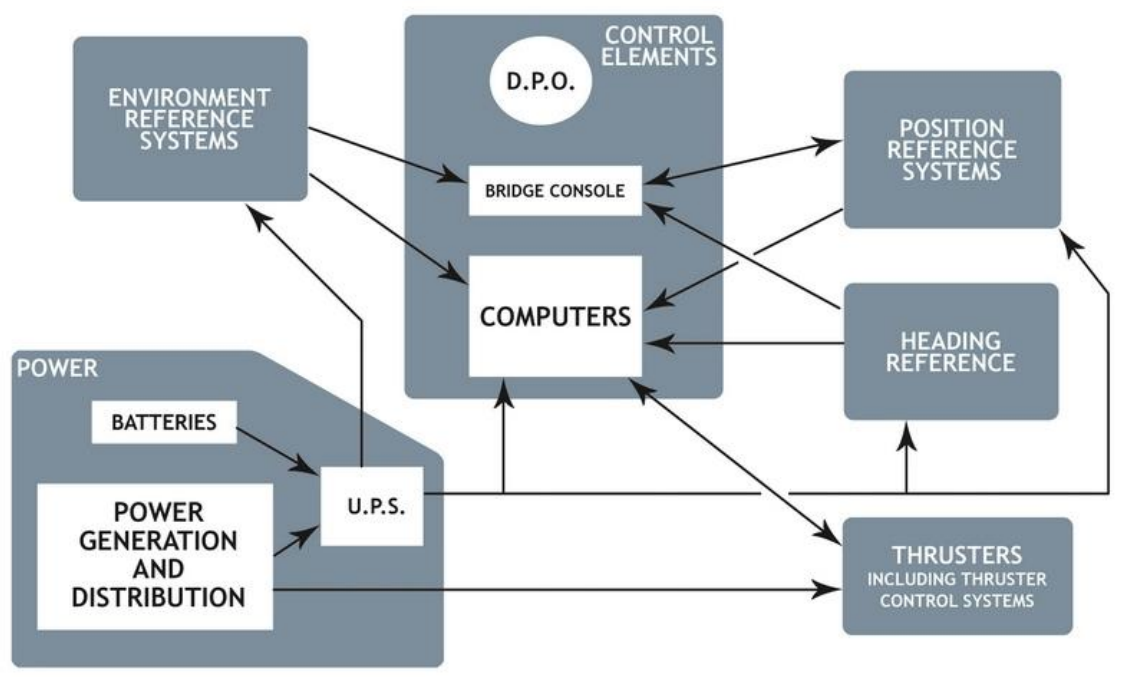

Figure 1. Integrated Ship Management System Diagram

Modern information technologies help increase the efficiency of ship navigation by:

- monitoring and control of ships using on-board identification systems;

- based on the infrastructure of effective information exchange;

- intelligent integrated airborne systems;

- the effectiveness of port systems based on services with common document management standards.

The set of marine equipment performing these functions is called marine technical equipment (propulsion and steering complex mechanisms, sources of various types of energy, mechanisms, assemblies, installations of all ship systems and devices). These are complex ergatic systems and are multi-circuit systems that include different types and various levels of control devices and systems that collect and process information about the status of various managed ship facilities and the external environment; the development is solved about the impact on objects and their implementation.

Communication technologies must successfully interact with terrestrial satellites and dedicated secure communication channels. In general, data should be transmitted exclusively in real-time, and only the positions of some vessels can be updated with a delay when the vessel went beyond signal reception. There may be a small error only if the ship moves at a minimum speed and a great distance. Marine information systems should be designed in such a way as to reduce the potential for accidents that arise from the "person error / individual device error." This will require creating systems to reduce the fundamental errors in the perception, communication, and decision-making that can occur onboard a ship or on shore. Another critical element of the system is standardization. Standardized development, based on separate modules of the subsystem, should be adapted to each vessel's functions, allowing sailors to adapt to the newly introduced new equipment quickly.

A user of a computer integrated control system (skipper) and a set of intellectual activity tools that could be combined into a single whole on the basis that they should get a solution to a common problem, namely: a guarantee of safe operation of ships, which forms a single and complex ergatic system (ergatic organism) in one case, and in another case, positioned as an intelligent system. Of course, if a ship uses a certain ergatic and at the same time intelligent system, then it has its specific properties, characteristics that can be provided by the developers of the system and depend on intrasystem integration. However, 
at the same time, with whatever options the system is purchased - this system involves minimizing production risks. As a result, a non-threatening level of navigation should be provided, which is set initially. This will lead to the fact that all countries with a fleet and supply sailors will have to switch on new methods and principles of work shortly - the introduction of modern high-tech equipment and the confident use of it.

\section{ACTION MECHANISM OF A SHIP COMPUTER-INTEGRATED NAVIGATION SYSTEM}

A qualitatively new stage of navigation is computer-integrated navigation systems that combine navigation directions: on electronic maps, according to sonar data, where information is transmitted in real-time, satellite navigation systems, etc. At the same time, a fundamentally new level of safety and navigation efficiency is achieved.

The hydroacoustic system work in an integrated system, where one of the subunits of the multi-beam echo sounder, working in real-time, brings it closer to solving the problem. The work of a multi-beam echo sounder: the collection of bathymetric data, forward and backward scattering data simultaneously in a wide field of view, the synergetics of signal processing in the framework of computer integrated navigation systems was considered in [11-13].

Management in such systems is implemented based on a mathematical model that describes the dynamics of behavior, which considers all the specifics of water navigation technic. A typified view of the principle of the computer-integrated navigation system of the vessel can be characterized as follows: a combination of computer intelligence with personal knowledge of the navigational staff; a priori information about the characteristics of a particular area of the terrain that is on the ship is compared with information received in real-time. Next, information is compared, and the proper location is determined, which enters the control system, where influences for actuators are formed.

Computer-based information technology control systems, which are part of integrated systems, provide a selection of performance indicators and optimization of such critical system properties as reliability, security, and manageability and are a vital vector in developing the economy of the water transport industry. The development of computer-integrated technologies in the ship's control systems involves developers of a wide range of software systems. They show their signs in the following areas: firstly, this is the analysis and synthesis of complex, autonomously independent automated control systems, including such complex computer systems, as neural networks that are built on the most complex computing resources; secondly, intelligent systems that perform the function of monitoring and controlling objects and processes around the globe through dedicated communication channels, and also anticipate the risks associated with the equipment involved in these networks; thirdly, diagnostics of the performance of these devices and control systems. The development and operation of such systems with software administration of technical means is closely related to the need for the highest scientific and engineering staff [14-16]. Based on existing engineering solutions for computer-integrated ship navigation systems, it can be argued that the quality level can be assessed according to the following criteria:

- graphic design and interaction with users (the interface should be consistent and intuitive);

- functionality (necessary levels of access rights should be provided);

- performance and stability (minimum reaction time);

- compliance with the terms of the Policy Rules for application developers;

- $\quad$ setting up the testing environment (to assess the quality of the application, you must configure the appropriate hardware);

- testing procedures (similar testing procedures help identify various types of problems with the quality of such applications).

When constructing such an independent information system, special attention should be paid to the fact that these systems belong to the dynamic class and their functional dependence is directly related to the standardization of the hardware and technological design of processes, which will fully reflect the direct purpose and implementation conditions, as well as, structuring the features of automatic control, which 
is directly related to the nature of the processes in the system. All integrated systems of the sphere use the principle of mathematical modeling based on the positioning function and have a mathematical model of ship movement. The use of this information, in combination with the processing of continuously incoming information from orientation systems and sensors, generates control signals to the power plant and the propulsion-thruster complex, with the help of which the real vector of external forces on the vessel (wind, current, excitement) is compensated. The system always uses information from orientation systems operating on different physical principles - sonar, radio wave, satellite, electromechanical, laser-optical, etc. The volume of tasks solved by various vessels' electronic control complexes and these complexes' structure is not the same. It depends on the degree of automation of the ship's control tasks. Electronic control systems for the vessel can consist of separate unrelated subsystems that solve some local issues. Electronic problem-oriented subsystems are combined into a single integrated ship system on modern ships, also called a shipboard integrated management complex. The integration system performs the following functions:

- automatic identification of ships, reception, and transmission to radio channels of navigation information, voyage information, and static information;

- determination of the coordinates of the vessel using the internal receiver, including using the differential mode;

- receiving and issuing static, travel data, text and binary messages to electronic cards;

- transmission of differential corrections via channels (base station function, mobile station function);

- issuing status information to the control and display panel and external equipment;

- the issuance of bearings calculated according to the coordinates of the ships and their coordinates and distances to these ships;

- assignment of appropriate operating modes to ship and coast stations, including assignment of areas, frequencies, radiation power, slots, report periods, number of repetitions of reports, and operation modes of repeaters.

Developing modern computer integrated technologies for water transport, like any other technological systems, needs to pay significant attention to the experiment. The primary purpose of the experiment is to study a specific object directly. Therefore, by changing to input processes and measuring processes at its output, it is possible to identify dependencies, a good display of the connections between the system's input and output. This concept in systems engineering is associated with the concept of the "state" of a system. System engineering in this area covers the issues of scientific planning, design, evaluation, design, and operation of systems and the problems of organizing working methods when creating systems. The result of navigation engineering is a set of universal system development methods suitable for adaptation and automation, the essence of which is the application of a systematic approach to decision making, ensuring an effective transition from the system concept to design solutions suitable for successful implementation and ultimately, to systematic products suitable for use.

\section{CONCLUSION}

The rapid development of information technology has led society to new horizons for modeling complex systems, namely computer integrated navigation systems, for which the main criterion is to ensure the safe movement of a moving object in absolute coordinates. However, with the proliferation of innovative means in the daily activities of shipping, one of the characteristics is the possession of scientific methods of data processing and decision-making. A problem has arisen that can be associated with properties such as the "human factor". It cannot be denied that the promotion of high technology, namely the cognitive structure, where ensuring navigation safety, to a greater extent, rests on the options of intelligent systems, will lead to the conventional disqualification of maritime experts. The procedure for disqualification of personnel on fleet ships will primarily entail that water transport experts put computer intelligence in the first place; that is, they rely more often on making decisions to ensure safe navigation for intelligent technical means. However, this is not all. The new computer-integrated navigation systems allowed the navigational staff to reduce their own production activity and not apply their individual knowledge and practical experience to enough extent, leading to negative consequences. 
Nevertheless, not everything is so sad, and the available computer integrated navigation systems and software were able to simulate safe navigation according to the set motion parameters. Moreover, the use of the cognitive structure of distributed knowledge allows the most efficient use of available resources and the shortest possible time to achieve the desired result. A consistent approach to the structure of computer integrated navigation systems and the organization of submodules enabled the user to focus on the model using the basic principles and terminology of a specific subject area.

\section{ACKNOWLEDGE}

We wish to thank Prof. V. Kychak, I. Prof. Trotsyshyn, Prof. O. Punchenko, and Prof. G. Bortnyk for their insightful comments on earlier drafts. We would also like to thank Vinnytsia National Technical University for the application of theoretical and practical research in the R \& D "Development of the theory and methodology of digital radio signal processing in real-time" (Ministry of Education and Science of Ukraine, Vinnytsia National Technical University); R \& D "Development of methods for designing a fiber-optic transmission system" (Ltd "Budivelnik-3", Vinnytsia National Technical University).

\section{REFERENCES}

1. Punchenko N.O., "Informaciyni Tehnologii: Suchasniy Stanta Perspektivi”, Pages 133-148, Disa Plyus, Ukraine, 2018.

2. Tsymbal, O., Bronnikov, A., "Decision-Making Information Technology for Flexible Integrated Manufacturing", Innovative Technologies and Scientific Solutions for Industries, Vol. 2, Issue 8, Pages 105$112,2019$.

3. Dehgani, R., Navimipour, N. J., "The Impact of Information Technology and Communication Systems on the Agility of Supply Chain Management Systems”, Kybernetes. Vol. 48, Issue 10, Pages 2217-2236, 2019.

4. Camero, A., Alba, E., "Smart City and information technology: A Review", Cities, Vol. 93, Issue 3, Pages 84-94, 2019.

5. Bagapova, G., Kobilova, N., Yuldasheva, N., "The Role of Distance Education and Computer Technologies in Teaching Foreign Languages", European Journal of Research and Reflection in Educational Sciences, Vol. 8, Issue 10, Pages 206-211, 2020.

6. Gallini, N. I., Makoveichuk, K. A., "Development of Intranet Solution Based on the Model of a United Single Information and Analytical Space Area of the University", IEEE Conference of Russian Young Researchers in Electrical and Electronic Engineering (EIConRus), Saint Petersburg, Pages 1388-1392, 2019.

7. Peruzzini, M., Pellicciari, M., Gadaleta, M., "A Comparative Study on Computer-Integrated Set-Ups to Design Human-Centred Manufacturing Systems", Robotics and Computer-Integrated Manufacturing, Vol. 55, Issue 1, Pages 265-278, 2019.

8. Delaram, J., Fatahi Valilai, O., "An Architectural Solution for Virtual Computer Integrated Manufacturing Systems Using ISO Standards”, Scientia Iranica, Vol. 26, Issue 6, Pages 3712-3727, 2019.

9. Sowjanya, P., "Computer-Aided Software İntegrated Automated Safety System”, International Journal of Computer Aided Engineering and Technology, Vol. 11, Issue 4, Pages 561-577, 2019.

10. Punchenko, N., Korchenko, O., Tsyra, O., Kazakova, N., \& Warwas, K., "Cognitive Technologies in the Professional Knowledge as a Means of the Optimizing Management Decisions", International Multidisciplinary Scientific: SGEM, Vol. 19, Issue 2, Pages 161-166, 2019.

11. Punchenko N., Levkovska M., Tsyra O., "High-Precision Technologies for Hydro-Acoustic Studies of Complex Bottom", Proceedings of the International Scientific and Practical Conference, Ukraine, Pages 176178, 2019.

12. Punchenko N.O., "Formuvannya Danih Zvorotnyogo Rozsiyuvannya Eholota Yak Umova Universalizacii Navigaciynoi Bezpeki”, Information Technologies and Automation Conference, Odessa, Pages 76-78, 2019. 
13. Punchenko N., Tsyra O., Nasibova V., "Selection of the Model as a Factor for Control of Digital Space-Time Processing of Hydroacoustic Signals In The Multi-Beam Echo Sounders", Processing, Transmission and Security of Information, Pages. 383 - 390, Wydawnictwo Naukowe Akademii Techniczno, Bielsku-Białej, 2019.

14. Punchenko N., Tsyra O., Kazakova N., "Computer Integrated Technologies as a Global Trend in the Development of Safety to Navigation of the Innovative Society", International Scientific Conference" ITCM2020, Ivano-Frankivsk, Pages 23-25, 2020.

15. Yılmaz S., Bayramoğlu K, Kaya K. D., “3D Printed Solar Catamaran Model Design and Embedded Sensing System Application", International Journal of 3D Printing Technologies and Digital Industry, Vol. 2, Issue 3, Pages 12-21, 2018.

16. Aygul, E., Yalcinkaya, S., Sahin, Y., "Microstructural analysis of sintered pure-titanium and titanium/hydroxyapatite (HA) surgical implant materials under different temperatures and HA doped conditions produced by powder metallurgy", Materials Research Express, Vol. 7, Issue 3, Pages 3540235411, 2020. 